\title{
Educational intervention for the awareness improvement and control programme design on Echinococcosis in Izmir, Turkey
}

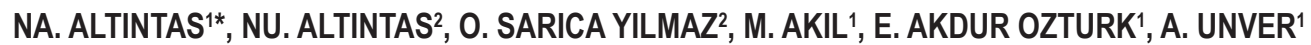

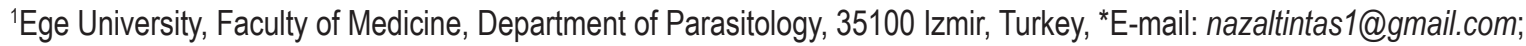 \\ ${ }^{2}$ Manisa Celal Bayar University, Faculty of Medicine, Department of Medical Biology, 45030 Manisa, Turkey
}

Article info

Received November 19, 2020

Accepted February 22, 2021

\section{Summary}

In Turkey, cyst hydatid disease (CHD) or cystic echinococcosis (CE) is publicly known as "dog cyst", a fatal and serious disease not only affects livestock husbandry and human health but also brings about economic loss to our country. According to the data of the Ministry of Health; number of annual cases was 408 in 2008, and this number reached 1,867 by the end of 2019. Cystic echinococcosis is especially taken up during childhood and emerged at an older age. They become exposed to the eggs of the tapeworm after close contact with an infected dog or its contaminated environment. The infected dogs also pass in their feces $E$. granulosus eggs that adhere to the dogs' hairs, and pass on to the children who are in the course of playful and intimate contact with the infected dogs. This study was to create the awareness of risk factors of CE among 10 different districts of Izmir province. Awareness raising seminars are essential component of this study because local people living in CE endemic areas, are crucial to continue and sustain the long-time effort that is needed to tackle this disease. In each district, 3 awareness raising seminars were held to the target groups: (a) in schools for students, teachers, administrators, (b) for general public, (c) for healthcare professionals. 4090 students attended to the trainings, 242 administrators and teachers who attended to the presentations together with the students, 524 people were attended to the trainings and 327 health workers attended to the trainings from different institutions. This study helped improving this situation by organising educational events for the rural populations for preventing transmission of the disease. This is the first educational intervention study regarding creating awareness on CE in Izmir Province which includes 10 districts between January 2019 to January 2020.

Keywords: Cystic echinococcosis; cyst hydatid disease; creating awareness; prevention

\section{Introduction}

Cystic echinococcosis (CE) is an important parasitic disease originated from animals and can be transmitted to other herbivorous animals and humans. The adult tapeworm inhabits in the intestine of some carnivores (called definitive or final hosts), and the larval phase develops in the intermediate hosts, in which humans are included. It is endemic in sheep-raising regions of the world, especially in regions of the Mediterranean littoral and large areas of Europe, such as the Iberian, Balkan, and Italian peninsulas and Turkey. As the disease poses a threat for public health, it is taken under control in developed countries. However, underdeveloped and developing countries still face problems with controlling this disease (Craig et al., 2007, Tamarozzi et al., 2017, Altintas Nuray

\footnotetext{
$\overline{*-\text { corresponding author }}$
} 
et al.,2020). Today, CE is included in the group of neglected diseases (WHO 2010).

Cystic echinococcosis is publicly known as "dog cyst", a fatal and serious disease not only affects livestock husbandry and human health but also brings about economic loss to Izmir province. Turkey is among the countries where this problem still poses a public threat. Although echinococcosis has been recognized in Turkey since 1861, a consistent state policy for disease prevention and control has not been developed and echinococcosis continues to be a major health and economic problem in Turkey. According to some of the local studies, $E$. granulosus infection in dogs ranges between $0.32 \%$ and $40 \%$. The prevalence of CE in domestic animals ranges from $3.5 \%$ to $58.6 \%$ has varied widely with geographical location (Altintas, 2003).

In humans, the estimated surgical cases rates ranged from 0.87 to 6.6 per 100,000 inhabitants between 1987 and 1994 (Altintas, 2003). The sero-epidemiological study conducted for the first time in $1999,3.45 \%$ seropositivity and $291 / 100.000$ (6/2055) prevalence were found in 2055 people living in and around Izmir city (Altintas et al., 1999). In other studies conducted in Izmir Province, the number of the cases and the years were found as follow; 591 cases between 1997 and 1998, 840 between 1997 and 2001, and 1.274 cases between 2001 and 2005 (Ertabaklar et al., 2003, Yazar et al., 2008). On the other hand, Turkey's six provinces (Ankara, Aksaray, Balikesir, Bitlis, Istanbul, Sanliurfa) were screened by ultrasound and 53 of a total 8618 people screened $(0.6 \%$; 1/163) were infected with CE (Tamarozzi et al., 2018). Considering all the results of these surveys approximately one of each $150-200$ people $(0.5-0.6 \%)$ can be considered to be infected with CE in Turkey. This is also an indication that one of the most important health problem in Turkey.

This disease has been included within the scope of notifiable diseases since 2005 in Turkey. Newer epidemiologic studies disclosed higher prevalence rates; According to the data of the Ministry of Health; number of annual cases was 408 in 2008, and this number reached 1,867 by the end of 2019 . According to this, the morbidity rate reported as 0.57 per 100.000 in 2008 was reported as 2.08 in 2019 (Altintas et al., 2020).

The main reason for facing this public threat in Turkey in such a large scope is because this topic has not yet become a priority for the authorities. The public awareness on this issue is very low, thus people try to protect themselves and their children with hearsay information that are wrong, useless and even sometimes unethical practices such as teaching kids to be afraid of animals or deplacing stray animals from their habitats in residential areas to far. So, CE urgently needs attention both for protecting public health and animal welfare as well as for ending such unethical practices.

Since 1863, many programmes and control measures have been employed in several countries and have had varying outcomes (Jimenez et al., 2002, Craig \& Larrieu 2007, Guisantes 2014; Irapedra et al., 2016). The public awareness on this issue one of the most important strategy to make great achievements in controlling the disease and in the reduction of the prevalence in CE. It was recognized that management of information related to the intervention measures and their effectiveness was necessary for the effectiveness of the program. Information for the public concerning the preventative measures that need to be adopted (Jimenez et al., 2002). Health education considered to be one of the most important tools for the control and prevention of CE. It is a multi-disciplinary activity that requires knowledge of medical sciences and of teaching and communication methods (Irabedra et al., 2016).

Exposure of humans to $E$. granulosus is common due to the lifestyle of the prople who live in close proximity to sheep and dogs. The disease is often seen in women aged between 30 and 50 years who are more likely to be in contact with animals in rural areas (Orsten et al., 2018, Yolasigmaz et al., 2006) such as the chosen districts of Izmir province. Most people live in rural areas and are engaged in animal husbandry in this area. The ignorance about this disease and unsafe practices expose people for be infected, and children are the most vulnerable. And CE poses risk to children who do not pay attention to hygiene and sanitation rules at early ages because this disease especially taken up during childhood and emerged at an older age. According to the records of the Ministry of Health, Izmir province is in fourth place with a total of 680 cases with 131 cases between 2010 and 2014, with 402 cases between 2015 and 2019 (Altintas et al., 2020). So, our study aims to take an initial step towards overcoming this problem by raising awareness and educating children, people and inform authorities. This is the first study on education intervention regarding creating awareness on CE in Izmir Province which includes 10 districts between January 2019 to January 2020.

\section{Material and Methods}

\section{Study Area}

This study was a descriptive study to create the awareness of risk factors of $\mathrm{CE}$ among different districts of Izmir province. Awareness raising seminars are essential component of this study because local people living in CE endemic areas, are crucial to continue and sustain the long-time effort that is needed to tackle this disease. The seminars were organised in 10 districts: Aliağa, Bayındır, Bergama, Karaburun, Kemalpaşa, Kiraz, Ödemiş, Selçuk, Tire and Urla (Circled in the Map) (Fig. 1). The selection of these regions was based on the predominance of the pastoral production system or mixed crop-livestock production systems because of mostly raising animals in these regions. Agriculture and livestock keeping are major activities for income generation. Most families keep at least one guard dog, and there are also large numbers of ownerless, stray dogs. But no data about the prevalence of E.granulosus in these regions.

\section{Study Design}

Health education was conducted through the schools, public 
Fig. 1. Selected ten districts in Izmir Province.

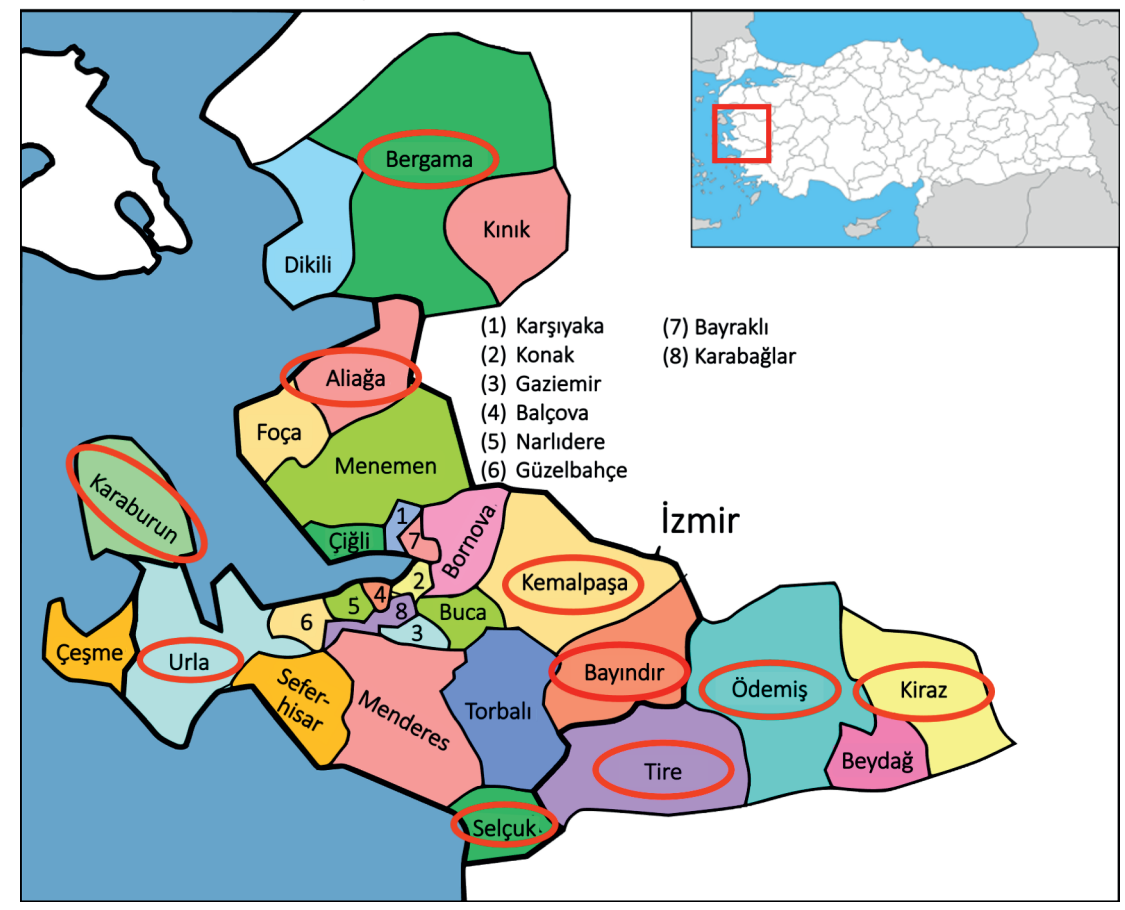

health centres and municipality meeting halls. Verbal, visual methods were employed during this training conducted from January 2019 to January 2020.

\section{Visiting stakeholders}

The study was carried out together with the public authorities in terms of decision-making and also in the process by which decisions are implemented. 40 visits were made to the various actors and stakeholders in 10 districts of Izmir Province as follow:

- Governorate: Information was given to the Governorate about the project, its rationale and the implementation. Governorate provided support by leading the public authorities at provincial and district level for contributing to the study - mainly for the provision of necessary resources such as activity venues, attendance of the healthcare professionals to the activities and schools' ownership of the project. It is important that the Governorate gives approval and permission to the Province and District Directorates of National Education to support the study.

- Province and District Directorates of National Education: Upon approval from Governorate, they provided permission to schools in their district to provide support and handle the necessary organisations for the implementation of activities at schools.

- Schools: Upon approval from the District Directorates of National Education, they organised the teachers, administrators and students for the presentations to be made by the Project Team. They also provided the venue (a classroom or a larger venue in the school, if available).

- Municipalities: Provided support for the public events (mainly through announcing and providing venue such as public halls). Municipalities have "District Directorates for Veterinarian Affairs", which have a critical role in awareness raising.

- Province and District Directorates for Veterinarian Affairs: The Project Team presented the project and delivered an awareness seminar to the Veterinarians and vet technicians. These professionals (being a member of the healthcare professional team in the districts) helped the Team on awareness raising seminars.

- Province and District Directorates for Health: The Project Team presented the project and delivered an awareness seminar to the Doctors and other health care professionals. These professionals helped the Team on awareness raising seminars.

- Neighbourhood/village representatives: They supported the project by announcing the awareness raising events and gathering public in these activities.

\section{Creating awareness for $C E$ disease}

Awareness raising seminars were organised in 10 districts of $\mathrm{Iz}$ mir Province: Aliağa, Bayındır, Bergama, Karaburun, Kemalpaşa, Kiraz, Ödemiş, Selçuk, Tire and Urla. In each district, 3 awareness raising seminars were held to the target groups: (a) in schools for students, teachers, administrators, (b) for general public, (c) for healthcare professionals.

a. Awareness raising activities for students, teachers and/or administrators in schools

Within the scope of the study, 26 schools were visited in 10 disticts and power-point presentations were made. The presentations pre- 


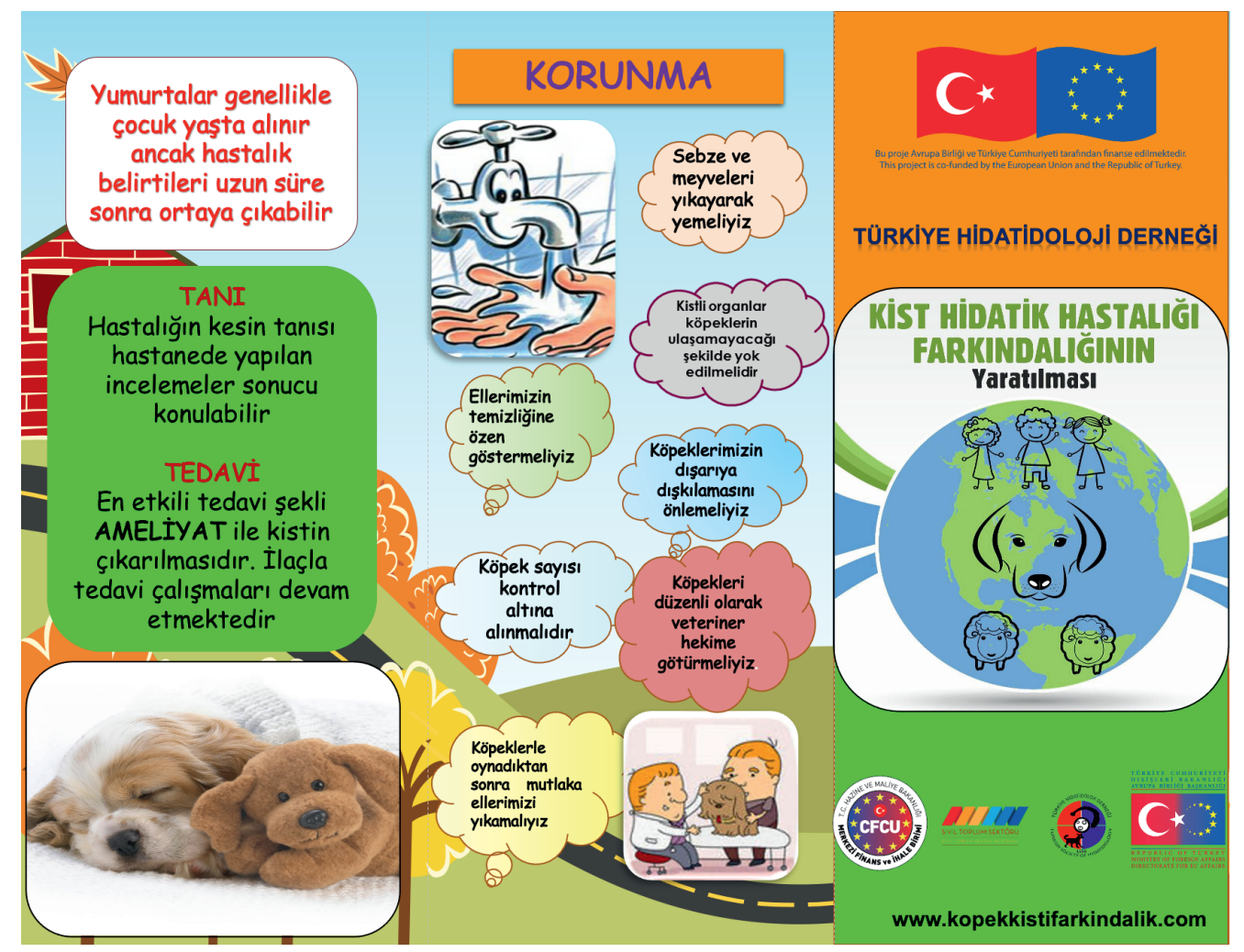

Fig. 2 A. Brochure prepared for students: Front side.

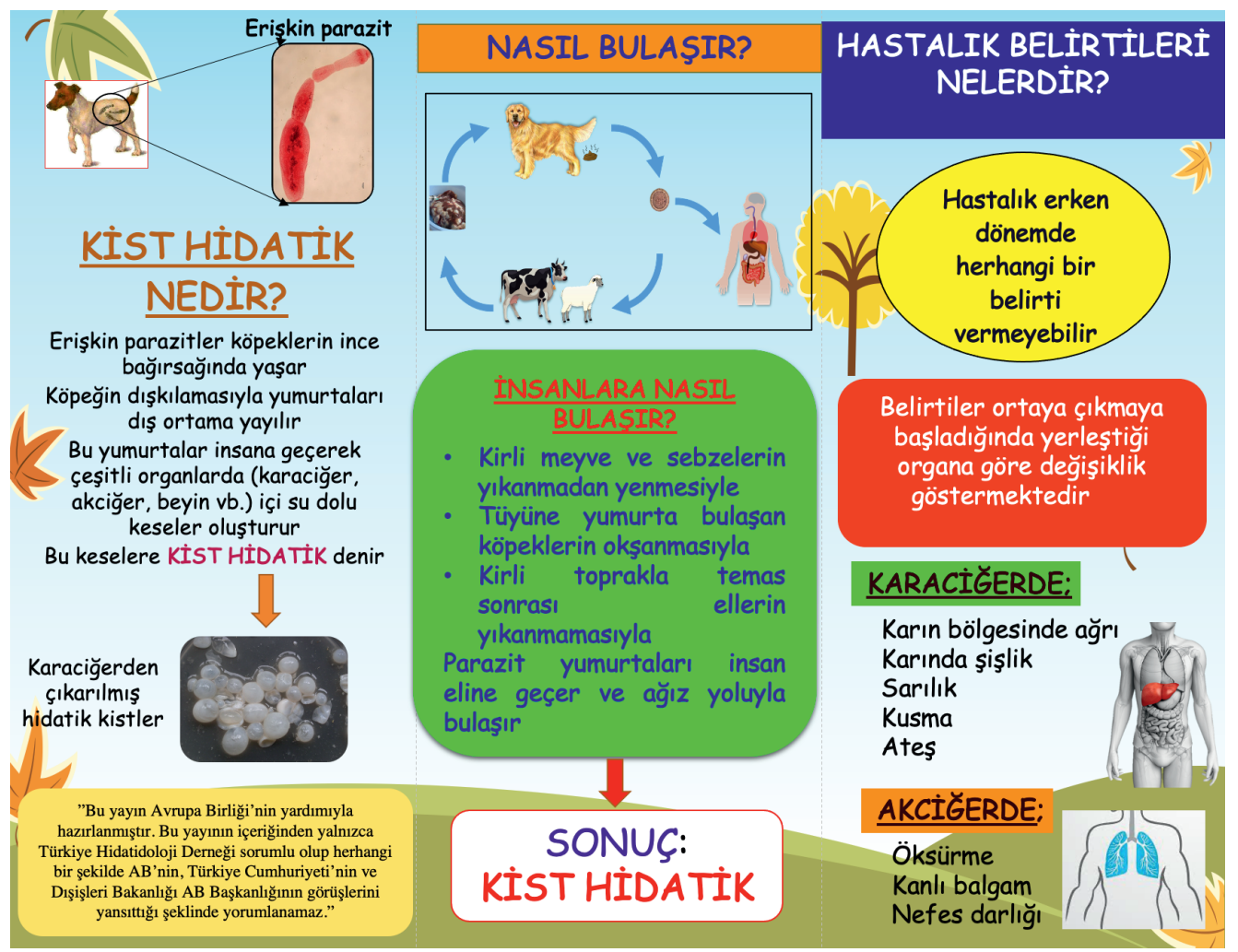

Fig. 2 B. Brochure prepared for students: Back side. 


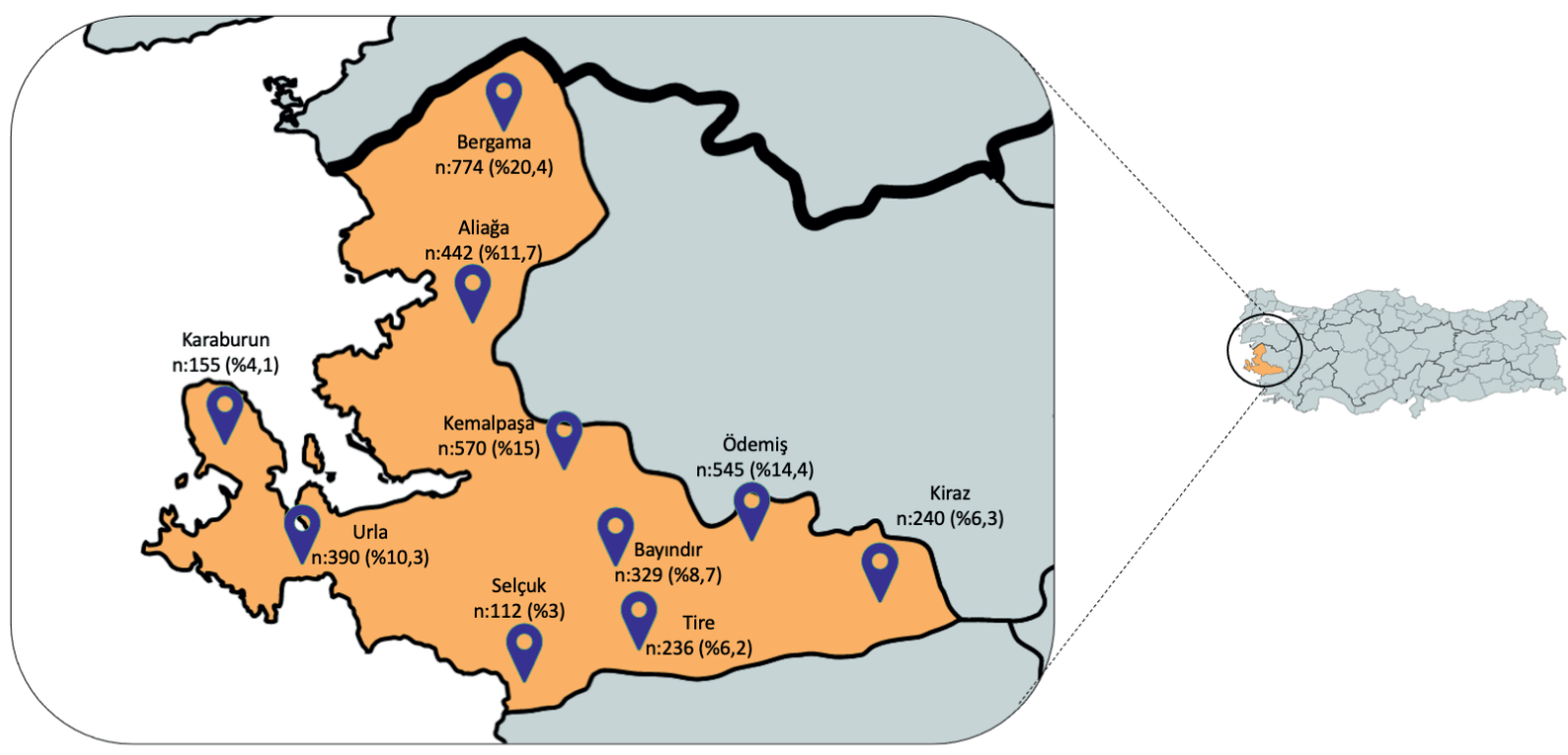

Fig. 3. The number of students in 10 districts.

pared according to the capacity of the students. Printed material such as posters and brochures were disseminated at these presentations and posters put on the walls or boards where students can see continuously. Elementary school 3rd and 4th year students were selected as the target audience.

\section{b. Awareness raising activities for general public}

Taking into account the public health perspective, this group of people are under threat as the nature of their daily life requires close contact with pet and farm animals. Yet, they were unaware of the risks they face according to their feedback were taken from them.

\section{c. Awareness raising activities for public servants / health care professionals}

Local health care providers (such as medical doctors, nurses, paramedical staff, lab technicians, veterinarians, biologists) are a vulnerable group as they are under direct threat, during the identification of the disease and treatment of humans and animals as well as during the meat inspections at slaughterhouses. The public authorities, on the other hand, are the decision makers either at points where problems occur or at local / provincial levels.

\section{Data management}

Information activities in schools, for public and for health professionals, analysis of data results, were delivered to the local authorities as well as the Ministry of Health and Ministry of Agriculture and Forestry.

\section{Role of the funding source}

The funder of the study had no role in study design, data analysis, data interpretation, or writing of the report. The corresponding author had full access to all the data in the study and had final responsibility for the decision to submit for publication.

\section{Ethical Approval and/or Informed Consent}

Ethical approval was obtained from the Ethics Committee of Ege University, Medical Faculty, Izmir, Turkey. Informed written consent was obtained from each participant.

\section{Results}

\section{Visiting stakeholders}

Within the scope of the Action, 40 visits were made to the stakeholders and employees of 40 different institutions to give information during the whole project period (12 months).

\section{Creating awareness for CE disease}

\section{a. Awareness raising activities for students, teachers and/or} administrators in schools

Necessary permit letters were sent from İzmir Governorship to Provincial Directorate of National Education and all District Governorships of the study. Then necessary permits for the activities in the schools were sent to the District National Education Directorates from these institutions.

Prior to this activity, easy-to-understand, PowerPoint presentations which enriched with animations and hand brochures were prepared in accordance with the knowledge level of the students. Elementary school $3 \mathrm{rd}$ and 4 th year students were selected as the target audience. The front and back sides of the brochure distributed to students are shown in Figure 2 below.

Even 4090 students attended to the trainings, questionnaires were filled by 3793 of the students. 1978 (52.1\%) of these students were 


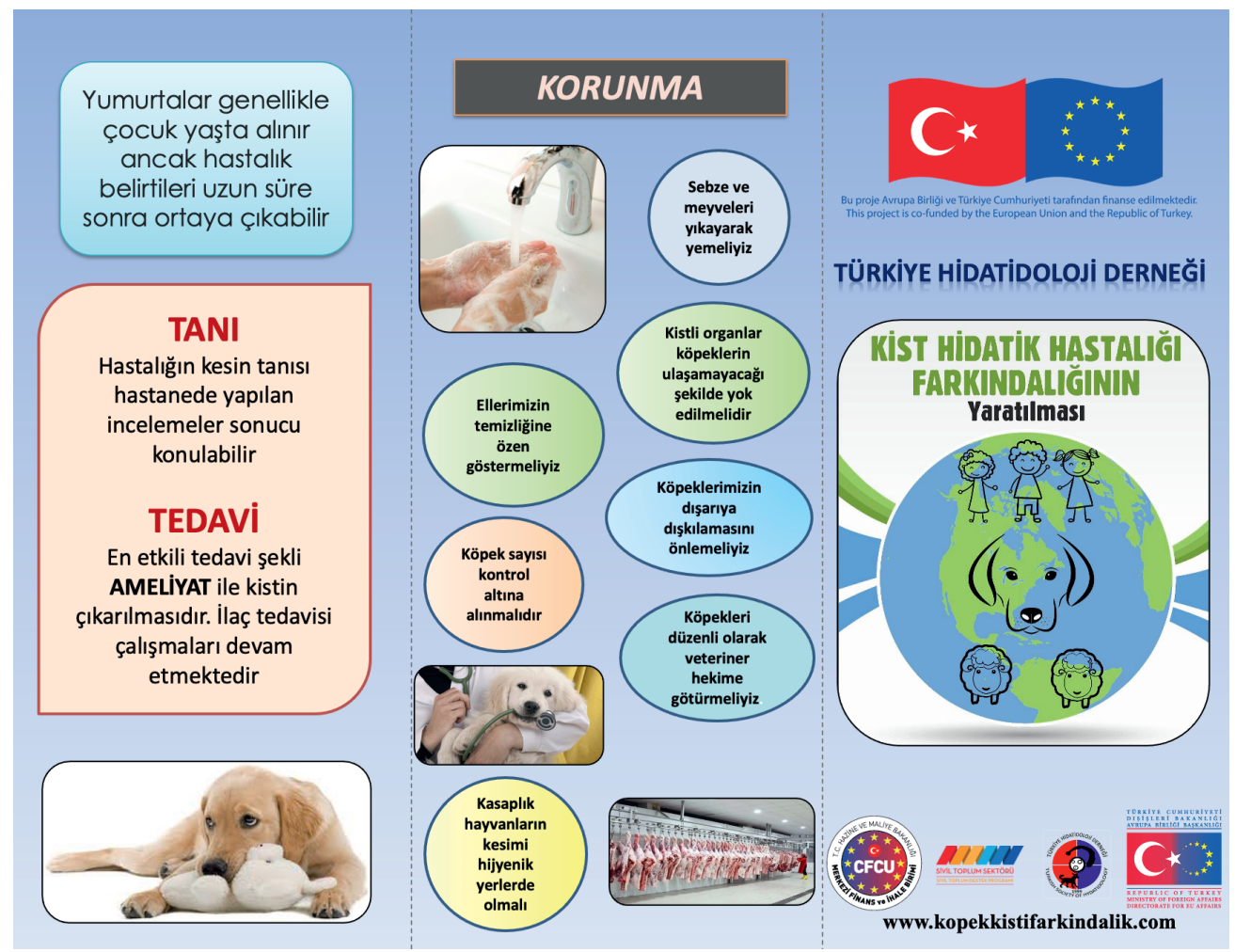

Fig. 4 A. Brochure prepared for public: Front side.

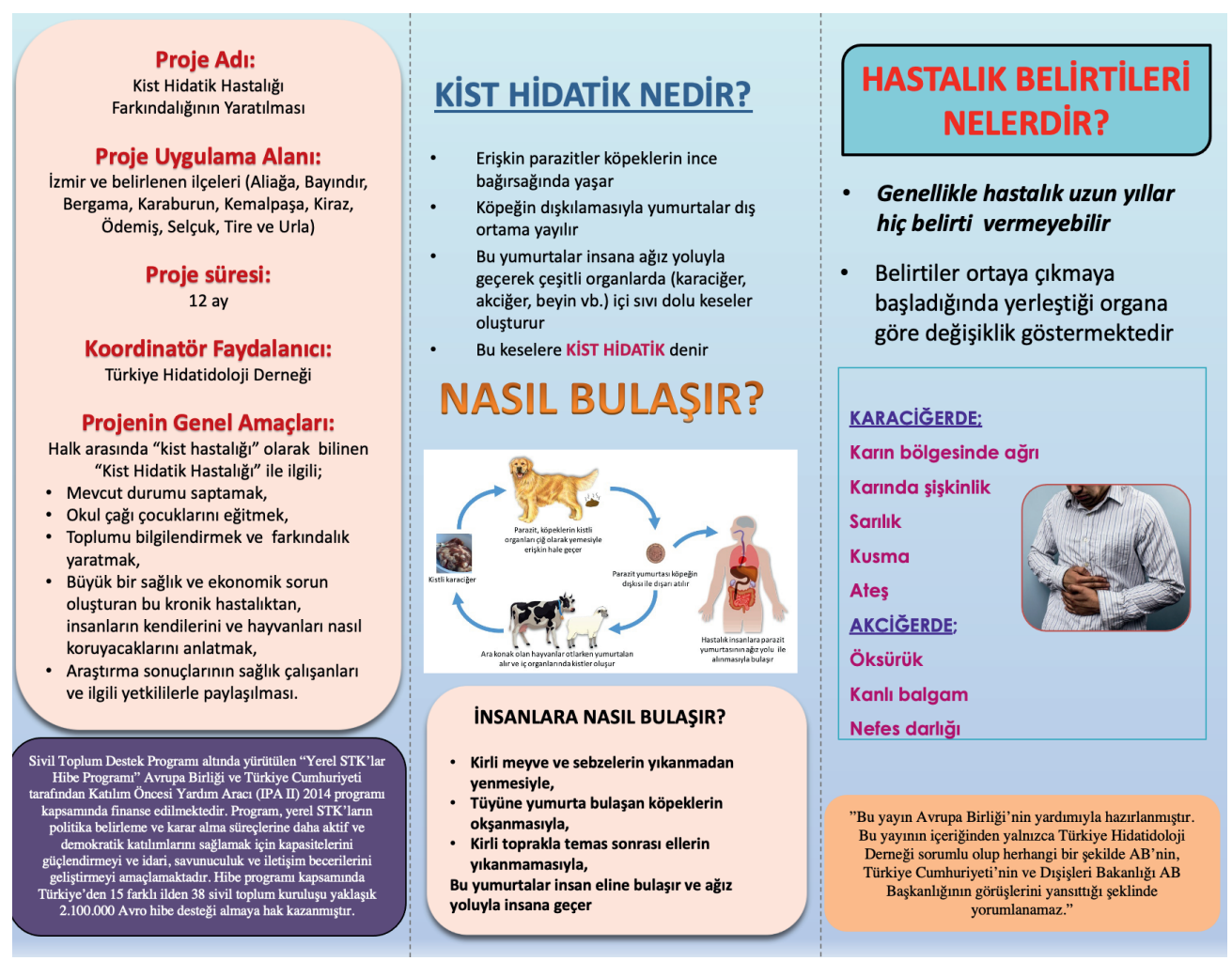

Fig. 4 B. Brochure prepared for public: Back side. 
Table 1. Distribution of the number of participants attending training seminars by gender.

\begin{tabular}{lccc}
\hline Attendees to the training seminars & The number of participants (\%) & Total \\
\hline NGO Management Course & Female (\%) & Male (\%) & 25 \\
Students & $14(56 \%)$ & $11(44 \%)$ & 4090 \\
Administrators and teachers & $2127(52 \%)$ & $1963(48 \%)$ & 242 \\
The people & $150(62 \%)$ & $92(38 \%)$ & 524 \\
Health care professionals & $305(58.21 \%)$ & $219(41.79 \%)$ & 327 \\
\hline Total & $183(55.96 \%)$ & $144(44.04 \%)$ & $\mathbf{5 2 0 8}$ \\
\hline
\end{tabular}

female students and 1815 (47.9\%) were male students. The total number of students in the districts indicated on the map below is shown (Fig. 3). According to questionnaire results, the majority of students $(94.2 \%)$ did not know anything about this disease before presentation. $93.1 \%$ students were stated that there were stray dogs in their environment. Nearly $90 \%$ of the students answered correctly the questions which were asked after presentation.

The total number of administrators and teachers who attended to the presentations together with the students was 242 . Of these, 150 were female (62\%) and 92 were male (38\%). After our activities, oral feedbacks were received from administrators and teachers. They informed that these awareness trainings were very effective on children.

\section{b. Awareness raising activities for general public}

Necessary permit letters were sent from Izmir Metropolitan Municipality to all District Mayors where the project will be carried out.

Programme of the seminar was included; a) Information about the content of the project and how to prevent and control cyst hydatid disease, b) Cyst hydatid disease for human health, c) Cyst hydatid disease for animal health, d) Studies carried out by veterinarians working in the districts (by the responsible veterinarian of the municipality in the district where the seminar is held).

During the presentations, hand brochures were distributed to the participants. These brochures contain information on the disease and how to prevent themselves. The front and back sides of the brochures distributed to the participants are shown in Figure 4.

As a result; 524 people were trained in 10 selected districts of Izmir and 305 were female (58.21\%), 219 were male (41.79\%). Before the presentation, it was observed that most of the participants had never heard about the disease before. After the presentation, feedback was received from the individuals that the presentations were effective and they were informed about the disease.

\section{c. Awareness raising activities for public servants / health care professionals}

Necessary permit letters were sent from the Izmir Governorship to the Provincial Directorate of Health and all district Health Directorates, to the Provincial Directorate of Agriculture and all the District Agriculture and Forestry Directorates and to the District State Hospitals within the scope of the study. During the presentations, hand brochures were distributed to the participants. A total of 327 people attending from different institutions were trained in 10 selected districts of Izmir. 183 people ( $55.96 \%$ ) who participated in the training consisted of women, 144 people were male (44.04 \%).

As a result, 5208 (2779 female, 2429 male) participants attended the training seminars. (Table 1 ).

\section{Discussion}

Cystic echinococcosis is common in people every part of the country but there is very little field work. Human cases are largely based on hospital records, and community-based screening studies are very few. However, with the local studies carried out in certain regions on people, dogs and slaughtered animals in recent years, it has been possible to obtain a little information about the condition of the disease. Although the present number of stray dogs and owned dogs is unknown in Turkey, according to some of the local studies, E. granulosus infection in dogs ranges between $0.32 \%$ and $40 \%$. The prevalence of $\mathrm{CE}$ in domestic animals ranges from $3.5 \%$ to $58.6 \%$ has varied widely with geographical location (Altintas, 2019). But we don't have any information in the Izmir province yet.

Increased awareness of zoonotic infections has been found to influence the management and control of these diseases (Othieno et al., 2018). Control measures should emphasise health education to encourage periodic trainings which is necessary to help below levels for continued transmission and regulate the slaughter of livestock in abattoirs and farms. People in rural areas need to be educated about proper control measures, such as; reducing transmission of the infection by proper slaughtering, safe waste disposal of infected animals, incineration of infected viscera, provision of safe drinking water, controlling of the dog population and their anti helminthic treatment (Fomda et al., 2015). Health education targets groups which attended to our education trainings that did not professionally concern the problem, such as school children or the public at large.

For $E$. granulosus the highest prevalence rates among humans and animals occur where livestock production is extensive, where large numbers of dogs are kept, and where dogs have access to carcasses of dead livestock or offal after uncontrolled slaughter 
(McManus et al., 2003, Babaoğlu et al., 2018). Animal husbandry is a predominant occupation in Turkey. In parts of the country, people make their living by raising animals, especially in central, eastern and southeastern Anatolia. Farming is the main occupation in rural areas thus rural population is at a high risk of acquiring infection. Almost every farmer keeps one or two dogs. Stray dogs are numerous, and prevention and treatment of infection in these dogs is very difficult. Turkey is a secular country; $99 \%$ of the people living in Turkey are Muslims. According to Muslim's custom, once a year during the sacrificial festival, tens of thousands of sheep and cattle are slaughtered, thus providing the stray dogs to the meat of infected intermediate hosts. Furthermore, livestock are slaughtered for daily meat requirements especially at rural areas (Altintas, 2003). Therefore, although infection control and prevention may seem to be an easy task, it is made very difficult because of the economic and social status of the people. Taking into account the public health perspective, these people are under threat as the nature of their daily life requires close contact with pet and farm animals. Proper education creating awareness and implementation of strict rules regarding disposal of remains of slaughtered animals can help to eliminate this disease. This study helped improving this situation by organising educational events for the rural populations for preventing transmission of the disease.

On the other hand, this study aimed also at raising awareness in the health workers group to help them understand the importance of the problem and how it can be solved by protecting public health while respecting human and animal rights. In addition to raising awareness in this target group, the study was carried out within the action also helped them determine the level of problem in the region, so that they can take decisions guided by information derived from scientific research. This study was conducted to improve the knowledge gaps, and attitudes of the people and health workers about CE infection in these regions. John et al., 2008, which showed that lack of adequate knowledge by health workers on echinococcosis detection was associated with poor management and high prevalence of echinococcosis. The disease is complex and dynamic with an evolving phase and quietly growing cysts. So it is difficult to diagnose, treat and cure. It is also important that more reliable epidemiologic data needed. Our results should be of useful for raising awareness among physicians of the presence of this infection and encourage improvement of case notification and cost benefit analyses in public health interventions.

Cystic echinococcosis is especially taken up during childhood and emerged at an older age. They become exposed to the eggs of the tapeworm after close contact with an infected dog or its contaminated environment. The infected dogs also pass in their feces E. granulosus eggs that adhere to the dogs' hairs, and pass on to the children who are in the course of playful and intimate contact with the infected dogs. The study suggests that education program for echinococcosis control should be initiated in school children because most infections acquire during childhood. This proposed project helped improving this situation by conducting a series of educational and awareness raising activities for the children such as; brochures, posters and presentations at primary and secondary schools for the children, where families, teachers and school administrations were also invited. In order to raise awareness about CE, we thought that students will inform their family members with the brochures they will take from school to their homes and affect their family members behavior. Feed back with questionarie from childrens and oral feed back from school teachers and from public showed us we had achievement informing them about the disease with our study.

Control programme development has been started to discuss with the authorities from Ministry of Health and Ministry of Agriculture after establishing the Turkish Association of Hydatidology (TAH) in 1999. TAH is the only Non Governmental Organization (NGO) in Turkey that works on "cystic echinococcosis". Then CE became a "notifiable disease" in 2005 by Ministry of Health. Collaboration among the departments of health, veterinary services and the enviromental agencies is important to take a control of this disease. Awareness programmes should set up a basis for the authorities to adopt corrective and preventive measures to avoid the disease (it can also set up for further and larger scale projects including humans in this field). Cystic echinococcosis continues to constitute a public health problem in endemic rural areas in Turkey. So, there is an urgent need for increasing the public awareness about the disease and to monitor the prevalence. Further studies needed to find out infection prevalence in urban and peri-urban areas.

In addition to the activities described above, Turkish Association of Hydatidology (TAH) have participated in and organised national and international meetings. The Universities in Izmir and other cities (Medical and Veterinary Faculties) to assist in the training of future professionals with better knowledge on the control of CE programme. Ministry of Health and Ministry of Agriculture and Forestry has been initiated in agreement to establih a control programme in 2019. Ministy of Health and Turkish National Committee of Zoonotic Diseases (Cystic Echinococcosis Subcommittee is included) were prepared the Turkey Zoonotic Diseases Action Plan (2019 - 2023). This Action Plan was included 4 objectives; 1) To raise public awareness about zoonotic diseases and prevention, 2) To conduct risk analysis and identify threats related to zoonotic diseases, 3) To develop and ensure the effectiveness of zoonotic diseases diagnostic laboratories throughout the country, 4) Monitoring, evaluation, coordination and planning. But based on the research and studies performed in Turkey fighting against echinococcosis will require a long-term strategy and solution even CE urgently needs attention both for protecting public health and animal welfare. Moreover, this is the first project to create awareness on CE in the Izmir Province, Turkey that covers the big sample-size and different target groups. These activities are mainly aimed to interrupt parasite transmission and ultimately reduce the burden of the disease. Final report derived from the results was sent to the local authorities as well as the Ministry of Health, Ministry of Agriculture and Forestry and Ministry of Education to be used 
for larger scale projects in this area, including codes of conduct and nationwide control programme.

\section{Conflict of Interest}

The authors do not have a conflict of interest.

\section{Acknowledgements}

The authors would like to acknowledge the contributions of the following: Ministry of Health, District Health Officers, in charges of health centres, and District Veterinary Officers in the districts visited, Province and District Directorates of National Education Officersand. We are grateful to Mr. Ugur Kolsuz who was the Deputy Governor of Izmir and responsible of European Union and Foreign Relations Office. We also thankful to Mrs. Yildiz Devran who is the Deputy Major of Izmir.

This work was supported by the CFCU/TR2014/DG/04/A1-04-EuropeAid/139044/ID/ACT/ TR-Grant Scheme for Grassroots Civil Society Organizations Programme (grant agreement number GRS-293). The funding body had no involvement in the conception, preparation and writing of the manuscript, in the viewpoints expressed, nor in the decision to submit this Article.

We also thank to our veterinarian colleaques who volunteered to help during the fieldwork: Sinan Okcuoglu, Adem Gorgulu, Mustafa Yalcin, Umut Polat, Saygun Urgen.

\section{References}

Altintas, N., Yazar, S., Yolasigmaz, A., Akisu, C., Sakru, N., KaraCASU, F. (1999): A sero-epidemiological study of Cystic Echinococcosis in Izmir and surrounding area. Helminthologia, 36(1): 19-23 Altintas, N. (2003): Past to present: Echinococcosis in Turkey. Acta Trop, 85: 105 - 112. DOI: 10.1016/s0001-706x(02)00213-9 AltintAs, N. (2019): Control / Elimination Programme of Cystic Echinococcosis in Turkey. 28 $8^{\text {th }}$ World Congress of Echinococcosis "Toward the Control and Elimination of Echinococcosis", 29 - 31 October, Lima, Peru

Altintas, Nu., Karamil, S., Turkum, O., Akil, M., Sakarya, A., BozKAYA, H., ŠoltYS, J., ALtinTAS, NA. A pilot comparative study between serological and genetic investigations in relationship to clinical outcomes on patients with cystic echinococcosis. Helminthologia, 57 (2): 91 - 99. DOI number 10.2478/helm-2020-0012

Altintas, N., Topluoglu, S., Yildirim, A., Uslu, H., Eksi, F., Ok, U.Z., Arslan, M.O., Kayalep, C., Secer, M., Kilic, S., Karaman, U., Beyhan, Y.E., Oncel, T., Okumus, B., Erol, U., Sertkaya, B., Gulyaz, V., Keskinkilic, B., Kara, F., Doganay, M., Alp Mese, E. (2020): Current Situation Report of Cystic Echinococcosis in Turkey. Turk Hij Deney Biyol Derg, 77 (3): 1 - 51

Babaoglu Oral, A., Soyder, A., Malatyal, E., Ertug, S., ErtabakLAR, H. (2018): Genotyping of Echinococcus granulosus isolates by sequencing of mitochondrial cytochrome $\mathrm{C}$ oxidase subunit 1 (cox 1) gene in Aydin. Mikrobiyol Bul, 52(2): 198 - 205. DOI:
$10.5578 / \mathrm{mb} .66711$

Craig, P., Budke, C., Schantz, P., LI, T., Qlu, J., Yang, Y., Zeyhle, E., Rogan, M. T., Ito, A. (2007): Human echinococcosis: a neglected disease? Trop Med Health, 35: 283 - 292. DOI:10.2149/ tmh.35.283

Craig, P.S., LarRieu, E. (2007): Control of cystic echinococcosis/hydatidosis: 1863 - 2002. In: Molyneux, H.D. (Ed) Control of human parasitic diseases. Amsterdam: Academic Press, p. $443-508$ Ertabaklar, H., Pektas, B., Turgay, N., Yolasigmaz, A., Dayangac, M., Ozdamar, A., et al. (2003): Cases of CE detected in hospitals in Izmir and it's surroundings between January 1997 - May 2001. Turkiye Parazitol Derg, 27(2): $125-128$

Fomda, B.A., Khan, A., Thokar, M.A., Malik, A.A., Fazlli, A., Dar, R.A., Sharma, M., Malla, N. (2015): Sero-epidemiological survey of human cystic echinococcosis in Kashmir, North India. PLoS One, 10(4): e0124813. DOI: 10.1371/journal.pone.0124813

GUISANTES, J.A. (2014): Control and prevention of hydatidosis. In: TURGUt, M. (Ed) Hydatidosis of the central nervous system. Berlin Heidelberg: Springer-Verlag, p. $305-316$

Irabedra, P., Ferreira, C., Sayes, J., Elola, S., Rodriguez, M., Morel, N., Segura, S., Dos Santos, E., Guisantes, J.A. (2016). Control programme for cystic echinococcosis in Uruguay. Mem Inst Oswaldo Cruz, Rio de Janeiro, 111(6): 372 - 377. DOI: 10.1590/007402760160070

Jimenez, S., Perez, A., Gil, H, Schantz, P.M., Ramalle, E., Juste, R.A. (2002): Progress in control of cystic echinococcosis in La Rioja, Spain: decline in infection prevalences in human and animal hosts and economic costs and benefits. Acta Trop, 83: $213-221$. DOI: 10.1016/s0001-706x(02)00091-8

John, K., Kazwala, R., Mfinanga, G.S. (2008): Knowledge of causes, clinical features and diagnosis of common zoonoses among medical practitioners in Tanzania. BMC Infectious Diseases, 2008(8):162. DOI: $10.1186 / 1471-2334-8-162$

McManus, D.P., Zhang, W., LI J., Bartley, P.B. (2003): Echinococcosis. Lancet, 362(9392): 1295 - 1304. DOI: 10.1016/S01406736(03)14573-4

Orsten, S., Boufana, B., Ciftcl, T., Akincl, D., Karaagaoglu, E., OzkuYumcu, C., AkHAN, O. (2018): Human cystic echinococcosis in Turkey: a preliminary study on DNA polymorphisms of hydatid cysts removed from confirmed patients. Parasitol Res, 117(4): 1257 - 1263. DOI: 10.1007/s00436-018-5807-9

Othieno, E., Ocaido, M., Mupere, E., Omadang, L., Oba, P., Okwi, A.L. (2018): Knowledge, Attitude, and Beliefs of Communities and Health Staff about Echinococcus granulosus Infection in Selected Pastoral and Agropastoral Regions of Uganda. J Parasitol Res, 2018: ID 5819545. DOI: $10.1155 / 2018 / 5819545$.

TamarozzI, F., Mariconti, M., CovinI, I., Brunetti, E. (2017): Rapid diagnostic tests for the serodiagnosis of human cystic echinococcosis. Bull Soc Pathol Exot, 110(1): 20 - 30. DOI: 10.1007/s13149017-0548-Z

Tamarozzi, F., Akhan, O., Cretu, C.M., Vutova, K., Akinci, D., Chipeva, R., Ciftcl, T., Constantin, C.M., Fabiani, M., Golemanov, B., Jan- 
ta, D., Mihallescu, P., Muhtarov, M., Orsten, S., Petrutescu, M., Pezzotti, P., Popa, A.C., Popa, L.G., Popa, M.l., Velev, V., Siles-LuCAS, M., Brunetti, E., Casulli, A. (2018): Prevalence of abdominal cystic echinococcosis in rural Bulgaria, Romania, and Turkey: a cross-sectional, ultrasound-based, population study from the HERACLES project. Lancet Infect Dis., 18(7): 769 - 778. DOI: 10.1016/S1473-3099(18)30221-4

WHO - World Health Organization. Working to overcome the global impact of neglected tropical diseases. First WHO report on neglected tropical diseases. Geneva: WHO; 2010
Yazar, S., Taylan, A.O., Hokelek, M., Polat, H., Yilmaz, H., Ozbilge, H., Üstün, Ş., Koltaş, İ.S., ERTEK, M., ŞAKRU, N. et al. (2008): Cystic echinococcosis in Turkey between $2001-2005$ years. Turkiye Parazitol Derg, 32 (3): 208 - 220

Yolasigmaz, A., Reiterová, K., Turk, M., Reyhan, E., Bozdag, A.D., Karababa, A.O., Altintas, Nu., Altintas, Na. (2006): Comparison of serological and clinical findings in Turkish patients with cystic echinococcosis. Helminthologia, 43(4): 220 - 225. DOI: 10.2478/ s11687-006-0041-x 